\title{
CORNEAL SUTURES: IS ROUTINE REMOVAL REALLY NECESSARY?
}

\author{
J. P. DANJOUX and A. C. RECK \\ Norwich
}

\begin{abstract}
SUMMARY
Three groups of patients were reviewed 1, 2 and 3 years after extracapsular cataract extraction to assess the incidence of problems related to nylon corneal sutures and the need for suture removal. A large percentage of patients were found to have suture-related problems and required or had previously undergone suture removal. These findings are analysed. The potential risk of sightthreatening pathology associated with corneal sutures that are left in situ suggests that routine suture removal about 3 months after surgery is to be recommended.
\end{abstract}

Following extracapsular cataract surgery, nylon corneal sutures are commonly associated with a variety of complications. Conjunctival inflammation, superior corneal vascularisation and pannus, giant papillary conjunctivitis, infective conjunctivitis and corneal ulceration are all potential complications which have been well documented. ${ }^{1-5}$ Suture removal may be required to reduce postoperative astigmatism, but in most cases sutures are left in situ unless they become loose or broken; this necessitates their removal, usually in the eye casualty department.

Jackson and Bosanquet ${ }^{6}$ reported that a high percentage of patients whose sutures had not been removed had suture-related problems after the first year. We have tried to appraise the overall trends related to the problems associated with corneal sutures in order to establish whether early routine removal is to be recommended.

\section{PATIENTS AND METHODS}

One hundred and eighty patients (three groups of 60) who had undergone extracapsular cataract extraction 1, 2 or 3 years previously were invited to attend for review. A corneal section had been performed on all patients and 10/0 nylon sutures (interrupted or continuous) used for closure.

One hundred and fifty-eight patients attended and were

From: Department of Ophthalmology, West Norwich Hospital, Norwich, UK.

Correspondence to: Mr J. P. Danjoux, FRCOphth, Department of Ophthalmology, West Norwich Hospital, Bowthorpe Road, Norwich NR2 3TU, UK. questioned about symptoms that may have been attributable to their corneal sutures such as irritation or discomfort. This was followed by slit lamp examination to assess the state of the corneal suture. Related complications such as inflammation, vascularisation or giant papillary conjunctivitis were recorded.

If the corneal sutures had been previously removed, the patients notes were used to determine the reason for removal.

Patients with loose or broken sutures underwent suture removal at the time of review.

\section{RESULTS}

Patients reviewed were subdivided into groups according to their symptoms and the condition of their corneal sutures. Those who had had their sutures previously removed were grouped separately.

Table I shows the breakdown for each year group. This information is illustrated graphically in Fig. 1. Abnormal physical signs attributable to loose or broken sutures were also recorded (Tables II, III).

The main complaints of symptomatic patients with loose or broken sutures were irritation or a foreign body sensation and watering, although 5 patients also described episodes of recurrent conjunctivitis.

\section{DISCUSSION}

With the passage of time an increasing number of patients require removal of corneal sutures as a result of associated problems. Even by the end of the first post-operative year $41.1 \%$ of patients reviewed had required suture removal. After the second and third post-operative years this had risen to $72.2 \%$ and $87.5 \%$ respectively. The chi-squared test for trend is significant at $p<0.001$.

A further $4.2 \%$ of patients were found, after 3 years, to have absent sutures - presumably as a result of progressive degradation. One would anticipate that a proportion of patients in the latter group would have had a broken or loose suture remnant at some stage.

Only $8.3 \%$ of patients had an intact suture after 3 years

Eye (1994) 8, 339-342 C 1994 Royal College of Ophthalmologists 
Table I. Corneal suture status at review

\begin{tabular}{|c|c|c|c|}
\hline & \multicolumn{3}{|c|}{ Years after cataract extraction } \\
\hline & 1 & 2 & 3 \\
\hline No. of patients & 56 & 54 & 48 \\
\hline Asymptomatic/normal suture & $25(44.6 \%)$ & $5(09.3 \%)$ & $0(00.0 \%)$ \\
\hline Asymptomatic/degraded intact suture & $8(14.3 \%)$ & $10(18.5 \%)$ & $4(08.3 \%)$ \\
\hline Asymptomatic absent suture & $0(00.0 \%)$ & $0(00.0 \%)$ & $2(04.2 \%)$ \\
\hline Suture previously removed: broken & $5(08.9 \%)$ & $15(27.8 \%)$ & $15(31.2 \%)$ \\
\hline Suture previously removed: astigmatism & $9(16.1 \%)$ & $8(14.8 \%)$ & $8(16.7 \%)$ \\
\hline Suture previously removed: ? why & $0(00.0 \%)$ & $1(01.8 \%)$ & $3(06.2 \%)$ \\
\hline Asymptomatic: loose/broken suture & $5(08.9 \%)$ & $6(11.1 \%)$ & $7(14.6 \%)$ \\
\hline Symptomatic: loose/broken suture & $4(07.2 \%)$ & $9(16.7 \%)$ & $9(18.8 \%)$ \\
\hline Sutures removed at review & $9(16.1 \%)$ & $15(27.8 \%)$ & $16(33.4 \%)$ \\
\hline Total previously removed & $14(25.0 \%)$ & $24(44.4 \%)$ & $26(54.1 \%)$ \\
\hline Total no. patients having sutures removed: & $23(41.1 \%)$ & $39(72.2 \%)$ & $42(87.5 \%)$ \\
\hline
\end{tabular}

and in all of these patients the suture was degraded on clinical examination. Macroscopic tissue reactions to 10/0 nylon corneal sutures ${ }^{7}$ and microscopic evidence of surface degradation after 3 months ${ }^{8}$ have been reported. The complications arising as a result of these pathological changes, in addition to breakage of $10 / 0$ nylon corneal sutures, have also been documented..$^{1-5}$

Over a quarter of patients who attended for review had either loose or broken sutures, $45 \%$ of whom were asymptomatic. As can be seen from Table II, all except 1 patient in the asymptomatic group had abnormal clinical findings related to the suture.

Of concern were those patients with loose or broken sutures who were symptomatic on questioning (usually with irritation or a foreign body sensation). Either they or their general practitioner had failed to recognise the significance of their symptoms. As is seen in Table III, there were abnormal clinical findings in a large number of patients; 2 patients in the 3 year post-operative group had developed giant papillary conjunctivitis. The most common finding in both groups was corneal vascularisation (Fig. 2).

Jackson and Bosanquet ${ }^{6}$ similarly reviewed patients 1, 2

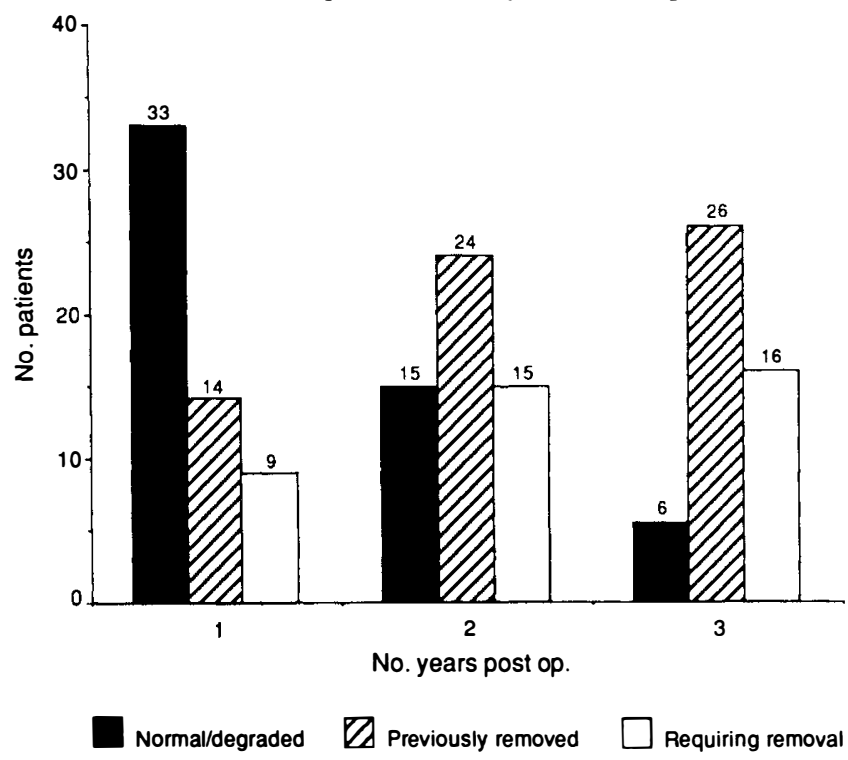

Fig. 1. Corneal suture status at review. and 3 years after cataract extraction. It is not possible to contrast their results directly with the results of this study, since Jackson and Bosanquet excluded from review those patients who had previously had their sutures removed. If, however, a similar subgroup from this study is compared, then the percentage of patients with broken or loose sutures (with or without symptoms) seen at review is similar in the 1 year and 3 years post-operative groups in both studies. For the 2 years post-operative group this study found broken or loose sutures in 50\% of patients who had not previously had suture removal, compared with $87.4 \%$ in the Jackson and Bosanquet study. This difference may be attributable to the small sample size in the Jackson and Bosanquet 2 year subgroup.

During the 16 week period in which patients were reviewed for this study, 42 patients attended eye casualty at the hospital with corneal suture-related problems requiring suture removal. Indeed, during this time 1 patient required admission for treatment of an acute bacterial endophthalmitis due to a broken corneal suture and stitch abscess which resulted in permanent impairment of vision in the affected eye.

There is some conflict of opinion as to whether corneal sutures should be routinely removed following cataract surgery. In our experience most surgeons remove sutures only if necessary (e.g. for astigmatism or when a suturerelated problem occurs). Justification for this is usually on the grounds of speeding up visual rehabilitation and avoiding delay in prescribing spectacles. Waiting until the wound is healed and the sutures can be removed usually means delaying spectacle prescription until 3 months post-operatively. Adopting this approach additionally

Table II. Abnormal clinical findings in asymptomatic patients with loose/broken sutures

\begin{tabular}{lccc}
\hline & \multicolumn{3}{c}{ Years after cataract extraction } \\
\cline { 2 - 4 } & \multicolumn{1}{c}{1} & 2 & 3 \\
\hline No. of affected patients & 5 & 6 & 7 \\
None & $1(20.0 \%)$ & 0 & 0 \\
Excess mucus & $3(60.0 \%)$ & 0 & $3(42.9 \%)$ \\
Conjunctival inflammation & $1(20.0 \%)$ & $2(33.3 \%)$ & $3(42.9 \%)$ \\
Corneal vascularisation & $3(60.0 \%)$ & $6(100 \%)$ & $5(71.4 \%)$ \\
\hline
\end{tabular}


Table III. Abnormal clinical findings in symptomatic patients with loose/broken sutures

\begin{tabular}{|c|c|c|c|}
\hline & \multicolumn{3}{|c|}{ Years after cataract extraction } \\
\hline & 1 & 2 & 3 \\
\hline No. of affected patients & 4 & 9 & 9 \\
\hline None & $3(75.0 \%)$ & $1(11.1 \%)$ & $1(11.1 \%)$ \\
\hline Excess mucus & $1(25.0 \%)$ & $3(33.3 \%)$ & $3(33.3 \%)$ \\
\hline Conjunctival inflammation & $1(25.0 \%)$ & $3(33.3 \%)$ & $6(66.7 \%)$ \\
\hline Corneal vascularisation & 0 & $8(88.9 \%)$ & $5(55.6 \%)$ \\
\hline Giant papillary conjunctivitis & 0 & 0 & $2(22.2 \%)$ \\
\hline
\end{tabular}

saves time in clinics. However, Baranyovits ${ }^{9}$ found that stabilisation of refraction sufficient to prescribe satisfactory spectacles did not occur for 3 months, following extracapsular cataract surgery. Stanford et al. ${ }^{10}$ investigated the timing of removal of sutures in the control of post-operative astigmatism. They found that although the time of removal did not affect the change in cylindrical power, the subsequent refraction was more stable when the suture was removed at 12 weeks, rather than any earlier. Furthermore, Parker and Clorfeine ${ }^{11}$ demonstrated that there was a similar shift from with-the-rule to againstthe-rule astigmatism over a 3 year period in patients with both intact and cut nylon sutures.

We feel that corneal sutures left in situ pose a definite threat of causing significant ocular pathology which may be potentially sight threatening - especially as many patients may be unaware that they have problems. Corneal sutures can usually be safely removed at 10-12 weeks when the healing wound will have reached sufficient strength to remain unsupported without stretching significantly. Some departments already routinely remove sutures at 12 weeks after extracapsular cataract extraction. By removing corneal sutures the risk of ocular discomfort and sight-threatening pathology associated with loose or

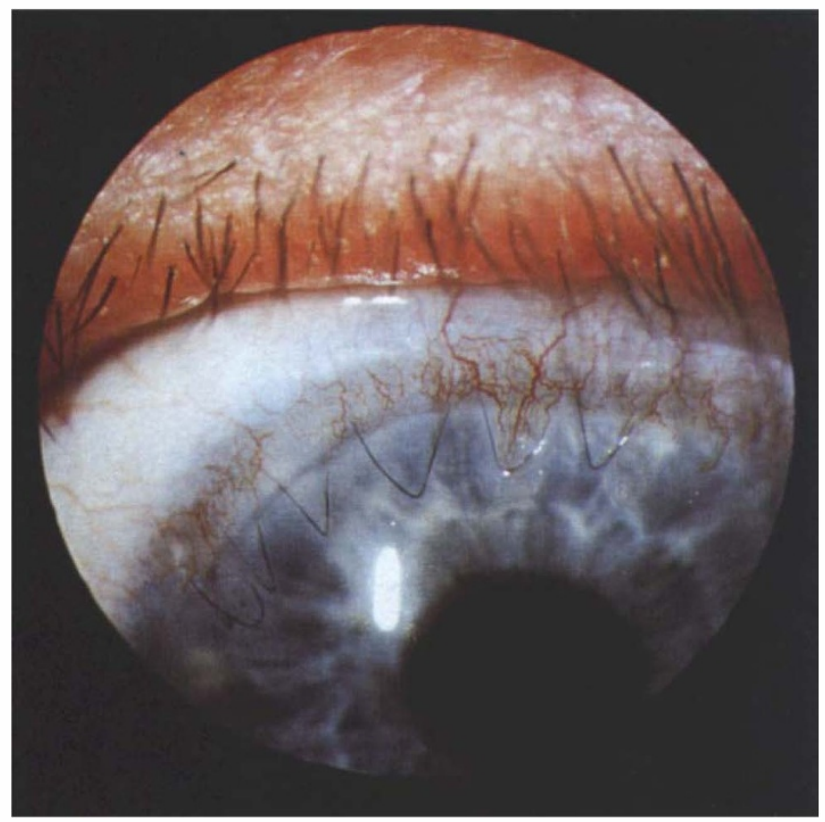

Fig. 2. Loose nylon corneal suture with corneal vascularisation. broken sutures is eliminated. In addition, visits to general practitioners or eye casualty would be reduced. There is anecdotal evidence that many patients with a standard corneal section can have spectacles prescribed at 6 weeks and sutures removed at 12 weeks without a clinically significant change in prescription. The authors are not aware, however, of any published data to substantiate this. Whilst this may be the case for patients with low cylindrical powers, many authors have reported marked changes in both cylindrical power and axis following suture cutting and removal in patients with over 2.5 dioptres of with-therule astigmatism..$^{10.12-15}$ Most patients, when the situation is explained to them, do not mind waiting an extra few weeks before their spectacles are prescribed.

Therefore the main argument against suture removal is the extra time in clinics that this entails. Perhaps the implementation of extended-role nursing would alleviate this problem. At the 10-12 week review, after being seen by the clinic doctor, the patient could have suture removal by a trained nurse, following which they would be instructed to visit their optician. There will always be a few patients deemed unsuitable for this procedure. This small number could have suture removal by a doctor, either in the clinic or as a minor operative procedure.

One possible contraindication to suture removal may be the presence of post-operative against-the-rule astigmatism. In such patients suture removal may worsen the astigmatism, producing an unsatisfactory spectacle prescription.

With technological advances in microsurgery allowing sutureless cataract surgery to be performed, the consequent absence of suture-related problems is yet a further advantage of such techniques.

In conclusion, we would advocate that there is a strong case for early routine removal of corneal nylon sutures, at about 12 weeks following extracapsular cataract extraction, in most patients.

Key words: Astigmatism, Cataract, Conjunctival inflammation, Corneal sutures, Corneal vascularisation, Giant papillary conjunctivitis.

\section{REFERENCES}

1. Shahinian L Jr, Brown SI. Post-operative complications with protruding monofilament nylon sutures. Am J Ophthalmol 1977:83:546-8.

2. Nirankari VS, Karesh JW, Richards RD. Complications of exposed monofilament nylon sutures. Am J Ophthalmol 1983;95:515-9.

3. Friedman T, et al. Giant papillary conjunctivitis following cataract extraction. Ann Ophthalmol 1984;16:50-2.

4. Wille H, Molgaard IL. Giant papillary conjunctivitis in connection with corneoscleral supramid suture knots. Acta Ophthalmol (Copenh) 1984;62:75-83.

5. Acheson JF, Lyons CJ. Ocular morbidity due to monofilament nylon corneal sutures. Eye 1991;5:106-12.

6. Jackson H, Bosanquet R. Should nylon corneal sutures be routinely removed? Br J Ophthalmol 1991;75:663-4.

7. Rijneveld WJ, et al. Comparison of the reaction of the cornea to nylon and stainless steel sutures. Doc Ophthalmol 1989;72:297-307.

8. McLellan KA, et al. Non-absorbable suture material in corneoscleral sections. Ophthalmic Surg 1989;20:480-5. 
9. Baranyovits P. Stabilisation of refraction following extracapscular cataract extraction. Br J Ophthalmol 1990;74: 486-9.

10. Stanford MR, Fenech T, Hunter PA. Timing of removal of sutures in control of post-operative astigmatism. Eye 1993; 7:143-7.

11. Parker WT, Clorfeine GS. Long-term evolution of astigmatism following planned extracapsular cataract extraction. Arch Ophthalmol 1989;107:353-7.

12. Jaffe NS, Clayman HM. The pathophysiology of corneal astigmatism after cataract extraction. Ophthalmology 1975; 79:615-30.

13. Stainer GA, et al. The natural and modified course of postcataract astigmatism. Ophthalmic Surg 1982;13:822-7.

14. Wishart MS, Wishart PK, Gregor ZJ. Corneal astigmatism following cataract extraction. Br J Ophthalmol 1986;70: 825-30.

15. Richards SC, et al. Long-term course of surgically induced astigmatism. J Cataract Refract Surg 1988;14:270-6. 